\title{
Levels of Linguistic Acts and the Semantics of Saying and Quoting
}

\author{
Friederike Moltmann
}

\section{Introduction}

In How to Do Things with Words, Austin (1975) introduced not only the notion of an illocutionary act, such as an act of asserting, requesting, promising, or asking a question, but also the notion of a locutionary act, which consists in various acts 'below' the level of an illocutionary act. A locutionary act includes what Austin calls a 'rhetic act', an act characterized, roughly, as the act of uttering the words in a sentence with a specific meaning and reference. A locutionary act also includes a 'phatic act', an act of uttering words, and a phonetic act, an act of producing sounds.

This chapter will outline a novel semantics of verbs of saying and of quotation based on Austin's distinctions among levels of linguistic acts. Austin's notion of a rhetic act is not a very clear one and tends to be considered problematic and insufficiently motivated. This chapter will propose a particular way of understanding the notion of a rhetic act and argue that it is extremely well reflected in the semantics of natural language, in particular in the semantics of verbs of saying and certain sorts of plural NPs in English (and German). This chapter will furthermore outline a novel semantics of quotation, making crucial use of Austin's distinctions among lower-level linguistic acts, a semantics that promises a unified and compositional semantics of quotation. Two ideas guide that semantics. First, quotations convey properties related to lower-level linguistic acts, Austin's phonetic or phatic acts; second, such meanings of quotations are strictly based on syntactic structure, namely, a lower-level linguistic structure as part of the syntactic structure of the sentence that is input to interpretation. Such lower-level linguistic structures may be phonetic, phonological, or morpho-syntactic structures. They will be interpreted, roughly, as properties of utterance tokens and as such contribute, in one way or another, to the semantic composition of the entire sentence. 
This semantics of verbs of saying and of quotation is cast within a more general act-related semantic theory of sentences and of attitude reports. While this theory ties in with recent act-based theories of sentence meaning (Jubien 200I; Moltmann 2003; Soames 20IO; Hanks 2015) in focusing on acts rather than abstract propositions, it differs fundamentally from those theories, in ways that will be crucial for the semantics of verbs of saying and of quotation. Most importantly, unlike Soames (2010) and Hanks (20I5), it does not consider sentences as standing for cognitive propositions, that is, types of cognitive acts (acts of predication). Rather it takes sentences to semantically act as predicates of various sorts of objects. These include entities such as claims, promises, requests, decisions, thoughts, and 'words', which are considered 'products' of illocutionary, cognitive, and locutionary acts in the sense of a product of Twardowski (I9I2, see also Moltmann 20I3, 20I4, to appear). As such they are bearers of truth or satisfaction conditions yet are particulars and dependent on the act that established them. In addition to such products, sentences may act as predicates of mental states (intentions, beliefs, hopes, etc.) and of modal objects such as needs and permissions (Moltmann 20I5b, to appear).

This view of the meaning of sentences has various conceptual and empirical motivations, especially in regard to the semantics of attitude reports (Moltmann 20I4, 20I7), modal sentences (Moltmann 20I5b, to appear) and truth predicates (Moltmann 20I5a). The semantics of verbs of saying and of quotation is another important application of the view, promising a novel, unified, and compositional semantic analysis.

An attitude report such as (Ia) on that view has the logical form in (Ib), where claim takes as its implicit Davidsonian event argument an act of claiming and product is a function mapping that act onto its product, John's claim:

(I) a. John claims that Mary is happy.

b. $\exists e(\operatorname{claim}(\mathrm{e}, \mathrm{John}) \&[$ that Mary is happy] $(\operatorname{product}(\mathrm{e})))$

The semantic value of the that-clause, [that Mary is happy], is a property of attitudinal objects, specifying their satisfaction conditions. Crucially, speech act reports such as (2a) with a quotational complement will have the very same logical form, as in $(2 b)$ :

(2) a. John says 'Mary is happy.'

b. $\exists \mathrm{e}\left(\mathrm{say}(\mathrm{e}, \mathrm{John}) \&\left[{ }^{\prime}\right.\right.$ Mary is happy'](product(e)))

However, the event argument of say is just a locutionary, not an illocutionary act, and the semantic value of the quotational complement, ['Mary is 
happy'], is a property of locutionary products, specifying, roughly, their form and semantic composition.

The form-related property that the direct quote in (2a) conveys is based strictly on linguistic structure, understood roughly in terms of Generative Syntax. The idea is that quotation involves a lower-level linguistic structure (a phonetic, phonological, or morpho-syntactic structure) as part of the syntactic structure of the sentence that is input to semantic interpretation (LF). I will suggest that this can be understood in terms of a threedimensional syntactic conception of syntactic structure, which permits lower-level linguistic structures to be represented on a separate plane and thus escape ordinary rules of syntax.

Direct quotes will have an ordinary syntactic structure as well as such a lower-level linguistic structure, and the interpretations of the two structures together will serve to characterize locutionary products in terms of a phonetic/phatic and a rhetic component. Mixed quotations involve a similar complex syntactic structure and dual semantics. Pure quotations, by contrast, will have only a lower-level linguistic structure as part of the overall syntactic structure of the sentence.

Unlike in standard formal semantics, the act-related conception of meaning permits an interpretation of a lower-level linguistic structure as part of the syntactic structure that is input to semantic interpretation, namely, as a property of utterances (phonetic or phatic products). This enables a compositional semantics of quotation based strictly on linguistic structure.

In the following, I will first outline the attitudinal objects theory of attitude reports with its main linguistic motivations, that is, the theory on which clausal complements act as predicates of attitudinal objects (illocutionary or cognitive products or mental states). I then extend the theory to verbs of saying (including think) based on the notion of a rhetic act. I propose a way of understanding the notion of a rhetic act and show that it is explicitly reflected in natural language. Finally, I outline the actbased semantics of quotation with a very brief sketch of a novel, threedimensional conception of their syntax.

\section{The Background: Sentences as Predicates of Attitudinal Objects}

The semantics of verbs of saying and of quotation this chapter will develop takes as its background the view that sentences do not stand for abstract or cognitive propositions, but rather act as predicates of a variety of objects. 
In the case of independent sentences, these are entities such as assertions, promises, questions, and demands, that is, illocutionary products. In the case of sentences embedded under attitude verbs, these will be various sorts of attitudinal objects. Attitudinal objects include illocutionary products as well as cognitive products, entities such as thoughts, judgments, and decisions. In addition, attitudinal objects include mental states such as beliefs, hopes, and intentions.

Attitudinal objects and kinds of them are extremely well reflected in natural language, namely, in the most common sorts of nominalizations of attitude verbs, assertion, request, promise, thought, decision, belief, intention, etc. Whereas John's assertion and John's intention stand for particular attitudinal objects, the assertion that $S$ and the intention to do $X$ stand for kinds of attitudinal objects.

It is common to consider nouns like assertion, promise, and belief to be polysemous, standing either for an act or for a proposition (as, for example, in Searle 1968). However, there are good grounds for considering the entities they stand for as sui generis entities - attitudinal objects (Ulrich 1976; Moltmann 2003, 2013, 20I4, to appear). Attitudinal objects are distinguished from acts and propositions in three main respects, well reflected in the applicability of the relevant predicates to products but not to the corresponding acts or, in general, to the corresponding propositions.

First, attitudinal objects have truth or satisfaction conditions, reflected in the applicability of various sorts of predicates of satisfaction, which would generally not apply to acts or propositions:

(3) a. John's claim is true.

b. ??? John's act of claiming is true.

(4) a. John's command was satisfied / complied with.

b. ??? John's speech act was satisfied / complied with.

c. ??? A proposition was satisfied / complied with.

(5) a. John fulfilled / broke his promise.

b. ??? John fulfilled / broke his act of promising.

c. ??? John fulfilled / broke a proposition.

Here '???' (and the weaker '??' and '?') means 'semantically unacceptable' or 'cannot possibly be true'.

Second, attitudinal objects (of the same type) enter the relation of exact similarity (expressed by is the same as) just in case they are the same in content, whereas other things need to be the case for acts to be the same. 
Thus, John's claim is 'the same as' Mary's just in case the two claims are the same in content, whereas for John's act of claiming (or John's speech act) to be the same as Mary's more needs to be the case than that. The same holds for commands versus acts of commanding and promises versus acts of promising.

Third, attitudinal objects have a part structure based on partial content and not the temporal part structure of acts or states. This is reflected in the way part of is understood with products: part of the assertion/promisel request/command can pick out only partial content, not a temporal part of an act.

Beliefs, intentions, and hopes are not products of acts, but mental states. Yet they share the characteristic properties of products, as do modal objects such as obligations, permissions, and needs, the entities playing the same sort of roles in modal sentences (Moltmann 20I5b, to appear).

A special class of attitudinal objects is illocutionary and cognitive products. They are to be understood as the (nonenduring) products of illocutionary or mental acts, in roughly the sense of Twardowski (19I2) (see also Moltmann 20I3, 20I4, to appear). In general, products but not actions are the bearers of representational or normative properties. Just like attitudinal objects in general, but unlike acts, products have truth or satisfaction conditions, enter similarity relations based on shared content, and have a part structure based on partial content, rather than the temporal part structure of acts. Yet products have properties of concrete objects as well, such as having a limited life span and the ability to enter causal and perceptual relations, and illocutionary products come with a physical realization (an utterance). Thus claims, the products of acts of claiming, can be made and overheard, and make people upset.

The action-product distinction also applies to phonetic and phatic acts as well as rhetic acts, which will be relevant for the semantics of verbs saying and of quotation.

For the semantics of attitude reports, I make use of Davidsonian event semantics (Davidson 1967). This means that cognitive or illocutionary acts are the implicit arguments of (nonstative) attitude verbs. Cognitive and illocutionary products then are the products of those Davidsonian event arguments, and as such can be obtained by a function product applied to acts. Sentences embedded under an attitude verb will act as predicates of the product of the event argument:

(6) a. John claimed that $S$.

b. $\exists e(\operatorname{claim}(e, J o h n) \&[$ that $S](\operatorname{product}(\mathrm{e})))$ 
Mental states will themselves be Davidsonian arguments of mental state verbs, and the product function will then simply map a mental state onto itself.

The semantics of attitude reports in (6b) is (almost) overtly reflected in the corresponding complex-predicate construction in (7), involving explicit reference to an attitudinal object (or to a kind of attitudinal object):

(7) John made the claim that $S$.

In fact, languages tend to show an alternation between the simple and the complex-predicate construction, which further motivates the semantics in (6b).

Not all attitude verbs have their clausal complement characterize the product of their event argument. Clausal complements of some attitude verbs instead serve as predicates of a contextually given attitudinal object, for example, a claim relevant in the discourse context. This is the case with response-stance verbs such as repeat, confirm, agree, and remind. ${ }^{.}$Thus (8a) has the analysis in (8b) for a contextually given claim or hypothesis $d$ :

(8) a. John confirmed that $S$.

b. $\exists e(\operatorname{confirm}(e, J o h n, d) \&[$ that S](d))

This difference in the semantics of the two sorts of attitude verbs is supported by the observation that response-stance verbs but not volunteeredstance verbs generally permit substitution of the clausal complement by an ordinary NP (John confirmed the hypothesis that S vs.??? John claimed the proposition that S). Moreover, response-stance verbs permit a reading of adverbs like partially quantifying over parts of the content of the contextually given attitudinal object, a reading unavailable for volunteered-stance verbs (Moltmann 20I7):

(9) a. John partly confirmed that Mary is incompetent.

b. ??? John partly claims that Mary is incompetent.

The same sort of difference will become relevant again for the semantics of verbs of saying.

The involvement of attitudinal objects in the semantics of attitude reports is also reflected in the semantic behavior of quantifiers and pronouns that can take the place of clausal complements. Such 'special' or 'nominalizing' quantifiers include something, everything, that, and what

I The notion of a 'response-stance verb' is due to Cattell (1978), who distinguishes it from that of a 'volunteered-stance' verb such as claim, request, think, etc. 
(Moltmann 2003, 2013). The relevant observation is that predicates acting as restrictors of such quantifiers generally are understood as predicates of attitudinal objects rather than of propositions:

(IO) a. John asserted something shocking.

b. John dreamt something nice.

c. John demanded something impossible to comply with.

Shocking, nice, and impossible to comply with express properties that can be attributed to attitudinal objects (assertions, dreams, and demands), but not abstract propositions (which cannot be 'shocking', 'nice', or 'impossible to comply with'). That is, they are properties that go with the relevant nominalizations (John's assertion, John's dream, or John's demand). This motivates the analysis of special quantifiers as nominalizing quantifiers, as below for (IOa) (Moltmann 2003, 2013, to appear):

(Iо) d. $\exists \mathrm{e}^{\prime} \exists \mathrm{e}\left(\operatorname{assert}(\mathrm{e}, \mathrm{John}) \& \operatorname{shocking}\left(\mathrm{e}^{\prime}\right) \& \mathrm{e}^{\prime}=\operatorname{product}(\mathrm{e})\right)$

Here the quantifier ' $\exists \mathrm{e}$ ' is introduced by something and ' $\exists \mathrm{e}$ " goes with the Davidsonian event semantics of the verb. On this analysis, special quantifiers do not provide arguments of the predicate, but, as nominalizing devices, introduce a new domain of entities on the basis of the meaning of the verb.

Furthermore, reports of sharing as below involve a special pronoun, the relative pronoun what:

(II) a. John asserted what Mary asserted.

(IIa) reports the sharing of a kind of attitudinal object, 'the assertion that $S$ ', rather than of a particular attitudinal object such as 'John's assertion that $S^{\prime}$, as in the analysis below (Moltmann 2003, 2013, to appear):

(II) b. $\exists \mathrm{e}^{\prime} \exists \mathrm{e}^{\prime \prime} \exists \mathrm{e}\left(\operatorname{assert}\left(\mathrm{e}\right.\right.$, John) \& e $\mathrm{e}^{\prime}=\operatorname{product}-k i n d(\mathrm{e}) \& \operatorname{assert}\left(\mathrm{e}^{\prime \prime}\right.$, Mary) \& $e^{\prime}=$ product-kind $\left.\left(e^{\prime \prime}\right)\right)$

Such reports of sharing will also be relevant for the semantics of verbs of saying.

There are constraints on reports on sharing discussed in Moltmann (2003, 20I3, to appear), which support the analysis in (Irb). Roughly the constraint is that the two attitude verbs need to involve the same force, but may differ in certain other respects such as strength:

(I2) a. ??? John promised what Mary asserted, that he will come back.

b. ??? John asserted what Mary demanded, that he will be back in an hour. 
(13) a. John suggested what Mary asserted.

b. John requested what Mary demanded.

When the two verbs are not identical, a decomposition of their meaning takes place into a more general attitude and a modifier, so that the shared object will be a kind of attitudinal object of the more general sort (Moltmann 2003, 2013).

If sentences act as predicates of attitudinal objects, the question is of course: what sort of property do they express? In their role as predicates of attitudinal objects, sentences need not specify a structured content since various sorts of attitudes need not involve any structure, such as implicit belief or knowledge (and neither do modal objects such as needs). Rather sentences can just specify satisfaction conditions of attitudinal objects, of a sufficiently fine-grained sort. Satisfaction conditions may be taken to consist in a set of worlds in which the attitudinal object is satisfied. However, using situations instead will give a more adequate, fine-grained notion of content. For that purpose, I will adopt notions from Fine's (2017) recent truthmaker semantics, which takes the content of a truth bearer to be bipartite, consisting of a set of exact truthmakers and a set of exact falsemakers. The role of sentences specifying the satisfaction conditions of attitudinal objects can then be captured by assigning sentences the following meaning (Moltmann 20I5b, to appear):

(14) For a sentence $S,[S]=\lambda \mathrm{d}[\forall \mathrm{i}(\mathrm{i} \| \mathrm{d} \rightarrow \mathrm{S}$ is true in $\mathrm{d}) \& \forall \mathrm{i}(\mathrm{i} \| \mathrm{d}$ $\rightarrow S$ is false in d)]

Here $\|$ is the relation of exact truthmaking that holds between a situation $s$ and an attitudinal object $d$ in case $s$ is wholly relevant for the satisfaction of $d . \|$ is the relation of exact falsemaking, which holds between a situation $s$ and an attitudinal object $d$ if $s$ is wholly relevant for the violation of $d$. Thus a situation of Mary's happiness is a satisfier of both John's claim that Mary is happy and John's desire for Mary to be happy, and a situation of Mary's being unhappy a violator of both that claim and that desire. ${ }^{2}$

One may object that this still does not give a sufficiently fine-grained notion of content. Verbs of saying and of occurrent thought may involve

2 (I4) treats declaratives and imperatives alike. However, imposing constraints on the properties and types of satisfiers, say differentiating between situations and actions, may allow distinguishing between the illocutionary act types associated with declarative and with imperative sentences, as well as, perhaps, between that-clauses and infinitival complements. 
complements that specify also a choice of words or concepts and their order, as in the sentences below:

(I5) a. John literally said that he was really incapable of doing the job.

b. John was thinking that he was really incapable of doing the job.

But this is precisely where the notion of a locutionary act comes into play. That-clauses may have an additional role and that is to characterize a verbal or mental act in terms of the choice and combination of concepts or words (with an intended meaning or referent), that is, in terms of a structure that results from a rhetic act. In other words, that-clauses will have two different meanings: [I] a property of attitudinal objects specifying their satisfaction conditions and [2] a property of the structured content associated with rhetic acts. The satisfaction-related meaning of that-clauses applies to attitudinal objects, whereas the structure-related meaning applies to the product of rhetic acts (which may be part of attitudinal objects, namely, illocutionary or cognitive products).

The distinction between actions and products also applies to rhetic and phatic acts, in tune with Twardowski (1912). ${ }^{3}$ The product of a rhetic act, but not the act itself, carries intended meaning-related and structurerelated features (a notion discussed in greater detail in the next section). The product of a phatic act (a 'token'), but not the act itself, carries only relevant form-related features (say phonological or morpho-syntactic features). ${ }^{4}$

\section{Locutionary Acts and the Semantics of Verbs of Saying}

\section{I Simple Verbs of Saying}

We will now see that the same semantics in (I4) carries over to verbs of saying, though they involve locutionary, not illocutionary acts. The focus will be on 'simple' verbs of saying, and only a few remarks about complex verbs of saying will be made later.

What I call 'simple verbs of saying' includes not only the verb say, but also write and think. There is good evidence that the semantics of these verbs involves locutionary acts, as parts of illocutionary acts, rather than

\footnotetext{
3 For phatic acts, this has been explicitly pursued by Twardowski's student Ingarden (193I).

4 The notion of a product of a phatic act in fact matches the familiar notion of a token (as opposed to an utterance act). A token has only relevant properties, properties of the linguistic structure the act is meant to realize such as phonological, morphological, or syntactic features.
} 
full illocutionary acts. First of all, reports of saying such as (I6) leave open what sort of illocutionary act was performed, say an assertion, a threat, or a promise: 5

(I6) John said / wrote that he will leave.

Say, write, and think may also take direct quotes as complements, of all three sentence types, which one might take to indicate that those verbs involve illocutionary rather than locutionary acts in their semantics: ${ }^{6}$

(I7) a. John said / wrote / thought 'I will leave.'

b. John said / wrote / thought 'leave!'

c. John said / wrote / thought 'what should I do?'.

The direct quotes are complements of the verb (Munro 1982): they fill in an obligatory argument position taking the very same place as could be taken by a special quantifier or pronoun, as in (I8) or in the pseudocleft construction in (19) (Grimshaw 2015):

(I8) a. John said / wrote / thought something, namely 'Leave!'.

b. What John said / wrote / thought was 'Leave!'.

(19) a. What John said / wrote / thought was 'I should leave!'.

b. What John said / wrote / thought was 'what should I do?'.

In fact, direct quotes of the three sentence types may satisfy the semantic selectional requirements of illocutionary verbs such as tell, demand, and ask (Grimshaw, ms). As such, they alternate with that-clauses (assertions), infinitival clauses (imperatives), and interrogative clauses:

(20) a. John told Mary that he will come / 'I will come.'

b. John demanded to be given one more day / 'Give me one more day!'.

c. John asked where the exit was / 'Where is the exit?'.

However, there are good arguments to the effect that say, think, and write do not involve illocutionary acts, but just locutionary acts - and thus that

5 Searle (1968) disputes the existence of such neutral occurrences of embedded sentences, but see Green (2015).

${ }^{6}$ All three verbs also allow for quotations with parentheticals and quotational inversion, constructions not available with non-quotational clausal complements:

(i) a. 'I will leave,' John said / wrote / thought.

b. 'I will leave,' said / wrote / thought John. 
direct quotes having the form of declaratives, imperatives, or interrogatives may just reflect locutionary and not illocutionary acts.

First, say, write, and think do not take interrogative or infinitival complements for the purpose of specifying a question or a request as the content of the attitude described by the embedding verb:

(2I) a. * John said / wrote / thought what he should do.

b. * John said / wrote / thought for Bill to leave.

Second, reports of sharing with say, write, or think and illocutionary verbs are impossible. Thus (22a) is impossible as a report of sharing relating to (22b) and (22c), and the same goes for (23)-(25):

(22) a. ??? John asserted what Mary said.

b. John asserted that Bill won the race.

c. Mary said that Bill won the race.

(23) a. ??? John said what Mary demanded.

b. John demanded that Bill should leave.

c. Mary said that Bill should leave.

(24) a. ??? John said what Mary asked

b. John said 'Did Bill win?'.

c. Mary asked 'Did Bill win?'.

(25) a. ??? John promised what he said.

b. John promised that he would help Mary.

c. John said that he would help Mary.

As discussed earlier, reports of sharing are about sharing kinds of products, and say and write just cannot share kinds of illocutionary products, but only kinds of locutionary products.

Also, reports of sharing with think and decide are impossible:

(26) a. ??? John thought what Bill decided.

b. Bill decided that they should leave the house / 'let's leave the house!'.

c. John thought that they should leave the house / 'let's leave the house!'.

Decisions are cognitive products on a par with illocutionary products such as promises or demands, by carrying satisfaction conditions with a worldword/mind direction of fit, to use Searle's (1969, 1983) term.

This means that the clausal complements of say, write, and think, including those that are direct quotes, serve to characterize locutionary, 
not illocutionary products. ${ }^{7}$ The Davidsonian event argument of verbs of saying will thus be just a locutionary act, though that act may be part of an illocutionary act. ${ }^{8}$ The overall semantics of locutionary act reports will then be the same as that for attitude reports:

(27) a. John said that $S$.

b. $\exists e\left(\operatorname{say}(e, J o h n) \&[\text { that } S]_{\text {loc }}(\right.$ product(e)))

That $\mathrm{S}$ here does not have the meaning given in (I4), but rather a secondary locutionary meaning, a property of rhetic products.

\subsection{The Nature of Rhetic Acts}

Clausal complements of verbs of saying, I have argued, serve to characterize products of locutionary, not illocutionary acts (or their mental counterparts). For Austin, locutionary acts consist of rhetic, phatic, and phonetic acts. Rhetic acts are meaning-related acts below the level of illocutionary acts. They are characterized as acts of using words with a specific meaning or reference. ${ }^{9}$ As stated, this would not really be a single act involving the use of a sentence, but a plurality of acts involving the words or relevant constituents of the sentence. ${ }^{10}$ Clearly, though, a rhetic act could not in fact be a mere plurality of acts of using the words in the sentence. Rather it should be a coordinated or structured plurality, namely, of acts of using expressions with particular meanings and with semantically relevant relations that will lead to the composition of the meaning of the sentence. Let us take the meaning of a sentence to be the property of illocutionary products given in (I4). Then a rhetic act will in fact be a plurality of acts of conveying semantic values of subsentential expressions as entering relations leading to the composition of the meaning of the entire sentence as the property in (I4). The product of such a plurality of acts will in turn be a plurality of products, namely, products of meaning-related acts involving subsentential occurrences of expressions in a particular meaningful

\footnotetext{
According to Austin (1975), indirect quotes, that is, that-clause complements of verbs of saying, characterize rhetic acts, whereas direct quotes characterize phatic acts (though Austin is not always consistent in what he takes indirect quotes to characterize, cf. Searle 1968).

${ }^{8}$ Note that as with belief, verbs of saying may describe states rather than acts, as below (Grimshaw 20I5):

(i) The sign says, 'It is forbidden to drive here.'

In that case, the product function applies to a state, as a carrier of representational properties, and maps it onto itself.

9 Austin actually gave various not entirely consistent characterizations of the notion of a rhetic act. I will just focus on one of them. See Searle (1968) for further discussion.

10 This was noted by Searle (1968).
} 
configuration. Natural language in fact reflects products of rhetic acts as pluralities, not as single entities, as we will see in the next section.

How can that-clauses express types of rhetic acts? A suggestion is that such an interpretation results when that-clauses are not fully interpreted, but instead the process of the semantic composition of the sentence is 'frozen' at a given point - that point depending, of course, on the speaker's intentions. This means that the composition of the products of a rhetic act may very well lead to an illocutionary product. Force-neutrality pertains to rhetic acts only insofar as they are not fully composed illocutionary products.

On this view, rhetic acts will be fundamentally different from acts of conveying a proposition, which Searle (I968) had proposed should take the place of rhetic acts. Rhetic acts are well reflected in natural language, as we will see in the next section; propositional acts hardly are.

\subsection{Explicit Reference to Products of Rhetic Acts}

Rhetic acts are explicitly reflected in one particular kind of expression in English, namely, plural NPs such as a few words, those words, and the words 'I forgive you'- 'words-NPs' for short. Words-NPs go with locutionary rather than illocutionary verbs, and what they stand for shows the characteristic properties of products of rhetic acts. ${ }^{\text {II }}$

In addition to that-clauses and direct quotes, the locutionary verbs say and write also take such NPs as complements:

(28) John said a few words / those words / the words 'I forgive you.'

Here words is used not as the plural of singular word, but as a plurale tantum, standing not for pluralities of individual expressions, but for pluralities of words with specific meanings in a meaningful configuration; that is, it stands for structured pluralities of meaningful elements. ${ }^{\text {I2 }}$

In some languages, the equivalent of words in that use differs morphologically from the ordinary plural of word. In German, Woerter is the

II Some observations about words-NPs have been made in chapter 4 of Moltmann (2013), where they have been taken as an indication for clausal complements of attitude verbs having the status of plural terms (for ordered pluralities) and as such as support for the Neo-Russellian Multiple Relations Analysis pursued in that chapter - mistakenly, as I now think.

${ }_{12}$ Note that words on that use is still semantically plural accepting numeral adjectives and plural quantifiers such as a few and supporting plural anaphora:

(i) a. those three words, 'I love you'

b. He said a few words, and then he said them again. 
ordinary plural of word and Worte the plural referring to words used with a specific meaning in a particular meaningful configuration (Moltmann 2013: 155). ${ }^{13}$ Words when standing for structured pluralities of meaningful elements occurs in fact also in the title of Austin's (1975) book, How to Do Things with Words, where words would translate in German as Worte (literally 'Wie man Dinge mit Worten macht'), not Woerter ('Wie man Dinge mit Woertern macht').

Words-NPs are force-neutral and can relate not only to a declarative sentence, but also to an interrogative and an imperative one, as below:

(29) 'Leave the house!' / 'When should I leave?', John himself has said precisely those words.

Force-neutrality is of course a mark of products of rhetic acts.

Related to force-neutrality is the observation that words-NPs do not go well with predicates of truth or satisfaction:

(30) a. ??? Mary's words, the words 'The world will end tomorrow' are not true.

b. ??? The words 'Finish the paper by midnight!' cannot be complied with.

c. ??? John fulfilled / broke the words 'I will help you!'.

This matches the observation that thought, which stands for products of cognitive rhetic acts, is not really good with truth predicates either - in ordinary speakers' intuitions:

(30) c. ?? John's thought that the world will end tomorrow is not true.

The products of rhetic acts are not bearers of satisfaction conditions, at least not in a non-derivative fashion.

Words-NPs when referring to the content of the acts described by the embedding verbs are possible only as complements of locutionary verbs such as say and write, not illocutionary verbs (Grimshaw 2015). Thus the relevant reading is unavailable below:

${ }_{13}$ Worte rather than Woerter is used also for naming the Ten Commandments. The Ten Commandments translates either as die Zehn Gebote, literally 'the ten commandments', or (less commonly) as die Zehn Worte, literally 'the ten words'. In the latter case, Worte is a superplural, standing for a secondlevel ordered plurality that consists of ten ordered pluralities of meaningful elements. Instead of die Zehn Worte, also das Zehnwort is used for the Ten Commandments, where -wort appears as a mass noun. As a mass noun, it still stands for the same thing as Worte, for an ordered second-level plurality of ordered pluralities of meaningful elements, just as Wort in das Wort Gottes, 'the word of God'. 
(3I) a. ??? John asserted a few words.

b. ??? John promised the words 'I am always ready to help.'

c. ??? John demanded / asked a few words.

The reason is that illocutionary verbs involve full illocutionary acts, not just locutionary or rhetic acts, and words-NPs can stand only for products of rhetic acts and not products of illocutionary acts. ${ }^{\mathrm{I}}$

Rather than characterizing the product of the act described by a locutionary verb, words-NPs may also provide the argument of other sorts of predicates:

(32) a. John repeated / understood / interpreted / read those words.

b. John believed / remembered / feared those words.

Here the words-NPs refer to the product of a contextually salient locutionary act; they thus have the same sort of function as that-clause complements of response-stance verb, standing for an entity that is independent of the event argument of the predicate. ${ }^{15}$

Not all locutionary verbs take words-NPs. Think does not and say to oneself does not really either:

(33) ??? John thought those words.

Words-NPs can stand only for physically realized products, not just products of cognitive acts. ${ }^{16}$

Words-NPs thus are an overt reflection in natural language of Austin's notion of a rhetic act (referring to the product of such an act). Natural language, by contrast, hardly displays (nontechnical) terms for abstract propositions, or, for that matter, for Searle's (1968) notion of a propositional act as an abstraction from an illocutionary act.

Illocutionary verbs generally do not take words-NPs. However, some of them, for example, demand and ask, take direct quotes:

(34) a. ??? John demanded / asked a few words.

b. John demanded 'help her!'

c. John asked 'When did you help her?'

${ }_{14}$ Note that words-NPs may stand for products of rhetic acts while acting as nominalizing quantifiers, rather than providing arguments of the predicate.

is With those verbs they allow for partially, unlike with say:

(i) a. ??? John partially said those words.

b. John partially repeated / understood / interpreted / read those words.

${ }^{16}$ This is also apparent from the way the more neutral verb add is understood. While add can describe a mental act in (ia), this is not possible in (ib), where it can only describe a discourse-related act:

(i) a. John added a few more expectations to his general hope.

b. ??? John added a few words to his thinking. 
This indicates that direct quotes can serve to characterize the locutionary part of an illocutionary act; whereas words-NPs can only stand for a rhetic product on its own.

This raises a general issue regarding the ontological status of locutionary acts. In what sense are locutionary acts parts of illocutionary acts? Can locutionary acts be performed without performing illocutionary act? For Austin, the linguistic acts of the various levels are ordered by the byrelation or what Goldman (1970) calls the relation of 'level-generation'. This is a form of composition of acts, but one in which lower-level acts could have been performed without performing the higher-level acts. Thus, if killing the king was done by pulling the trigger, the killing has the trigger-pulling as a non-temporal part and the pulling of the trigger could have been done without thereby killing the king. Certainly there are locutionary acts that are performed without performing illocutionary acts, say utterances for the purpose of grammatical exercise and entertaining thoughts for mere consideration. There is also an alternative view, though, according to which a locutionary act is an abstraction from an illocutionary act (Searle 1968). In that case, a locutionary act would be a part ontologically dependent on the whole and could not be performed independently.

Abstraction explains best the possibility in natural language of reference to illocutionary acts in disregard of the locutionary acts by which they are performed. An example is reports of sharing with illocutionary acts that would involve very different physical realizations (phatic acts). Thus, (35a, b, c) can be true at once:

(35) a. John asserted the same thing as Mary (that Bill won the race).

b. John whispered that Bill won the race.

c. Mary screamed that Bill won the race.

This even holds for reports of sharing with locutionary acts. Thus, (35d) may be true while also $(35 \mathrm{~b}, \mathrm{c})$ are true:

(35) d. John said the same thing as Mary.

Let us call the kinds of products reported as shared in $(35 \mathrm{a})$ and $(35 \mathrm{~d})$ 'thin illocutionary products' and 'thin rhetic products', respectively. Roughly, as an abstraction from a 'full' illocutionary product, a 'thin' illocutionary product will have only those properties relating to its conditions of satisfaction and force (or direction of fit), but not properties regarding its physical realization or choice of names or concepts. A similar condition would individuate a 'thin' rhetic product. 
Also, when using nominalizations, we seem to have a notion of an illocutionary product that is at least not dependent on the phatic act by which it is produced. Thus 'the very same assertion' could have been made in English by using a softer voice or by way of writing. Note that independently of speech acts we have a notion of an act that need not have the lower-level act that generates it as an essential part. The killing of the king could have been done by throwing a bomb instead of by pulling the trigger.

\subsection{Complex Verbs of Saying}

Besides simple verbs of saying, there are semantically complex verbs of saying. I will just make a few remarks about one such type of verb, manner of speaking verbs. Manner of speaking verbs behave just like simple verbs of saying, permitting in general that-clauses, direct quotes of the three sentence types, but not interrogatives or infinitival clauses representing the content of what would be an imperative:

(36) a. John whispered / screamed / muttered 'I will come' / that he will come.

b. John whispered / screamed / muttered 'who did that?' / * who that did.

c. John whispered / screamed / muttered 'Come!' / * for Bill to come.

Moreover, they may take NP-complements, including words-NPs:

(37) John whispered / screamed / muttered something /a few words.

Like simple verbs of saying, verbs of manner of speaking don't permit sharing with illocutionary verbs:

(38) a. ??? John whispered the same thing that Mary asserted / demanded / asked.

b. ??? John whispered the same thing that Mary asserted / demanded / asked.

This would indicate that manner of speaking verbs involve locutionary products just like simple verbs of saying. However, reports of sharing with a manner of speaking verb and a simple verb of saying are impossible:

(39) a. ??? John said what Mary whispered.

b. ??? John said what he screamed. 
By contrast, reports of sharing are possible with different verbs of manner speaking:

(40) a. ?(?) John screamed what Mary whispered.

b. ? John shouted what Bill yelled.

This indicates that manner of speaking verbs involve both a rhetic and a phatic act, whereas simple verbs of saying involve only a rhetic act. The possibility of reports of sharing with different manner of speaking verbs moreover suggests that manner of speaking verbs are underlyingly composites of a simple verb say and a manner of speaking modifier characterizing the phatic act (Grimshaw 2015).

To summarize, rhetic and locutionary acts play a central role in the semantics of simple and complex verbs of saying, which in general do not involve full illocutionary acts in their semantics.

\section{The Semantics of Quotation}

\section{I Quotation in General}

Direct quotes, as described so far, serve to characterize both the product of a rhetic act and the product of a phatic act, where the rhetic and the phatic act make up the locutionary act as (part of) the Davidsonian event argument of the embedding verb. The purpose of this section is to give a rough outline of a more general semantic theory of quotation according to which quotations convey properties of phatic products. This theory makes crucial use of Austin's distinction among levels of linguistic acts and a novel syntactic view of quotation, which permits treating quotation in a compositional and strictly semantic fashion. In the context of this chapter, this theory can be presented only in roughest outline with just a few central applications. A full formal development and a more elaborate discussion of the existing literature on quotation has to await another occasion.

Quotation presents major challenges for standard formal semantics. One such challenge is to deal with quotation within a compositional semantics since the phenomenon of quotation appears to militate against a compositional semantic treatment (Pagin and Westerståhl 20I0). Another challenge is to develop a unified account of pure (4Ia), direct (4Ib), and mixed (4IC) quotation: ${ }^{17}$

${ }^{17}$ For more on pure and mixed quotation, see Maier (20I4a, 20I4b). 
(4I) a. John said 'shhh'.

b. John said 'I will come.'

c. John said that he 'resides' in Paris.

Pure quotation differs from direct quotation in that it is not generally meaning-conveying and does not make up a sentential complement of an illocutionary or locutionary verb.

The standard view is that pure quotations are expression-referring terms, managing, in some way, to refer to the relevant expression type, by acting as descriptions (Geach 1972) or as names (Reichenbach 1947), or involving a demonstrative (quotation marks) pointing to a displayed token (Davidson 1969, 1979; Clark and Gerrig 1990; Cappelen and Lepore 2007; de Vries 2008), or else by 'presenting' it (Washington I992; Saka 1998). ${ }^{\text {I8 }}$ Direct quotations on the standard view require a different treatment since they contribute both a content (a proposition) and a form and thus cannot just act as expression-referring terms. ${ }^{19}$ Mixed quotations also contribute a content and a form, though the latter may either characterize the reported speech act as in (Ic) or some contextually given speech act. The standard view tends to consider both direct and mixed quotation pragmatic phenomena quite distinct from pure quotation. The standard view generally admits that quotation of various sorts cannot be treated compositionally and be based on the interpretation of a formal syntactic structure.

Standard formal semantics has difficulties with quotation because of one of its fundamental assumptions, namely, that the meanings of sentences are abstract propositions, a view that has recently been challenged by philosophers such as Jubien (200I), Moltmann (2003, 20I3), Soames (2010), and Hanks (2015), who argue in favor of an act-based notion of sentence meaning. A central aim of this chapter is to show that quotation provides an important application of an act-related conception of sentence meaning according to which sentences function as predicates of various sorts of objects, including products of illocutionary, locutionary, or cognitive acts. For the treatment of quotation (and of verbs of saying), this has the crucial advantage that sentences may express both content-related and form-related properties, to be predicated of products of locutionary and illocutionary acts. ${ }^{20}$

${ }^{18}$ The view that pure quotations are referential terms can also be found in Recanati (2000).

19 A unified treatment has been pursued though in the Davidsonian tradition by Cappelen and Lepore (2007).

20 The theory of quotation of Ginzburg and Cooper (2014) can also be considered an application of an act-related view of meaning to quotation. It shares similarities with the present approach to quotation, for example, by making use of 'locutionary propositions' for direct quotation. However, its 


\subsection{Pure and Direct Quotation}

The central idea regarding the semantics of quotation is that expressions can be interpreted not just by assigning them their usual semantic value, but also as properties of products of lower-level linguistic acts. This shift in interpretation, moreover, is not arbitrary or 'pragmatic', but rather has a strict syntactic basis. It is based on a lower-level linguistic structure being part of the syntactic structure that is input to interpretation. I will sketch this theory first for pure and direct quotation and then indicate how it extends to mixed quotation.

By way of illustrating the idea, it suffices to first stay with the verb say. Say takes a pure quotation as complement in (4Ia), repeated below:

(42) a. John said 'shhh'.

Pure quotations as in (42a) function as complements since they fill in an obligatory position and can be replaced by special quantifiers like something, allowing the inference from $(42 a)$ to $(42 b)$ :

(42) b. John said something.

As with that-clauses and direct quotations, pure quotations as complements may serve to characterize the product of the described event, though this must be a phatic or phonetic act, not a rhetic act. In (42a), for example, the pure quotation serves to characterize the product of a phonetic act.

A pure quotation as complement of say may also characterize a phatic act. This even holds for sentential quotations, which may in fact be pure quotations rather than direct quotations. The difference between sentential direct quotations and pure quotations is particularly clear in German. A sentence as a pure quotation must appear in NP-position, in the middle field, whereas as a direct quotation it must follow the verb: ${ }^{21}$

(43) a. weil Hans endlich 'Ich liebe dich' sagen kann because John finally 'I love you' say can 'because John can finally say 'I love you"

b. weil Hans endlich sagen kann 'Ich liebe dich' because John finally say can 'I love you' 'because John can finally say 'I love you'

empirical motivations and theoretical framework are rather different, and the space of this chapter does not permit a more detailed discussion.

${ }^{21}$ For similar syntactic observations about Dutch, see de Vries (2008). 
Whereas (43a) can report only a linguistic ability (the ability to pronounce a particular sentence, say), (43b) can report the readiness to express an emotional state (or the ability to admit to one).

The semantics of (42a) will then be as below, with the pure quotation predicated of the product of the phonetic act that is the Davidsonian argument of the verb:

(42) c. $\exists e(\operatorname{say}(e, J o h n) \&[\operatorname{shhh}](\operatorname{product}(e)))$

The question now is, how are pure quotations able to express properties of products of phonetic or phatic acts? The proposal is that this is so because pure quotations involve a lower-level linguistic structure as part of the syntactic structure of the sentence that is input to interpretation (L(ogical) $\mathrm{F}($ orm)). More precisely, a pure quotation may involve several lower-level linguistic structures as part of LF, a syntactic and a phonological structure, say. For the purpose of this chapter, I will just give some suggestions of how this idea may be spelled out syntactically. A full syntactic development will need to await another occasion.

First, a few general remarks about the syntax of pure quotation are needed. Pure quotations can obtain categorial specifications as NPs and fill in positions requiring an NP, as in (42a), but they may also occur in positions in which no complements may appear, such as in close appositions as in (44b) and following verbs that take no complements as in (44b):

(44) a. the word 'hello'

b. John went 'Hey, hey, hey'.

I will assume that pure quotations form quotational phrases (QPs). The syntactic structure of (42a) will then roughly be as below:

(42) d. John [said $\left.\left[[[\text { shhh }]]_{\mathrm{QP}}\right]_{\mathrm{NP}}\right]_{\mathrm{VP}}$

Following Giorgi (2016), one may assume that the head Q of a quotational phrase reflects a quotational pause. ${ }^{22}$

The new suggestion, then, is that $\mathrm{Q}$ is a special category that will act as a sort of coordinator, setting up a sort of coordinate structure involving other syntactic planes in a three-dimensional syntactic structure (Goodall 1987; Moltmann 1992). On standard three-dimensional syntactic theories of coordination, coordination involves a three-dimensional syntactic

${ }^{22}$ Giorgi (2016) makes use of a phrase KP for (direct) quotation where K reflects the comma intonation. However, close appositions do not involve a comma intonation, as opposed to ordinary appositions (the poet, Goethe vs the poet Goethe). 
structure, so that ordinary grammar applies to the various different planes representing the different conjuncts or disjuncts. The difference with quotation would be that the lower-level linguistic structures of quotations are represented in other planes precisely in order to escape application of rules of ordinary grammar. That is because quotations need not be grammatically correct, may come from other languages, and involve structures below the relevant linguistic level of the rest of the sentence. The structures in the other planes will all be interpreted as properties of products of phonetic or phatic acts, and their conjunction (intersection) will make up the semantic value of the entire quotation. Thus, shbh in (42a) will have a phonetic structure on a plane different from that of the rest of the sentence and that structure will be interpreted as a property of products of phonetic acts.

With this brief sketch of the syntax of pure quotation, let us turn to the difference between pure and direct quotation. A clause that has the status of a pure quotation has only lower-level linguistic structures, including possibly a syntactic structure that is as such not input to semantic interpretation. It thus does not have a syntactic structure on the same plane as the LF-structure of the sentence. By contrast, a direct quote also has a syntactic structure that is input to semantic interpretation, which allows it to express a property of products of locutionary acts as well. That structure is the structure of a main clause, not an embedded clause, which explains the 'shifted' interpretation of indexicals in direct quotes (Giorgi 2016, Grimshaw, ms):

(47) a. John $n_{\mathrm{i}}$ said 'I $\mathrm{I}_{\mathrm{i}}$ will come'.

b. ${ }^{*} \mathrm{John}_{\mathrm{i}}$ said 'he $\mathrm{e}_{\mathrm{i}}$ will come!'

Direct quotation exhibits selectivity, which means that not everything in the quotation marks matters for characterizing the phatic act in question, but only whatever features the speakers intends to matter. This means that direct quotation may involve just partial lower-level linguistic structures. As with pure quotation, the level of structure(s) that is to play a characterizing role also depends on the speaker's intentions (in fact more so than with pure quotation).

Direct quotation will express a conjunction of two properties: a property of rhetic products and a property of phatic or phonetic products. The property of rhetic products is based on the ordinary syntactic structure of the complement clause; the property of phatic products is based on a lower-level linguistic structure on a different plane. 
This account of direct and pure quotation considers quotation a semantic phenomenon, based on syntactic structure. It is compositional because of the particular way sentential meaning is conceived. The account differs fundamentally from current approaches to quotation where the utterance of the quotation, the token, matters for what the quotation contributes to the meaning of the sentence, both in the tradition of Davidson (1969, I979; Cappelen and Lepore 2007) and within the more recent identity theory of quotation (Washington 1992; Saka 1998). On the present theory, the semantic contribution of quotation is based on structure, and the quotational structure is interpreted as a property of tokens.

The present approach does not take pure quotations to necessarily form referential terms, unlike the standard view. Pure quotations may but need not act as referential terms, and in fact, their primary use ought to be predicative rather than referential since pure quotations express properties (of tokens). As a matter of fact, quotations may occur as syntactic predicates, namely in as-phrases with the verbs translate and pronounce:

(48) a. She translated red as 'rouge'.

b. She pronounced 'red' as 'rett'

As requires predicative, rather than referential complements (John as a father, Mary treated John as a brother), and thus the pure quotations in $(48 \mathrm{a}, \mathrm{b})$ must be predicative. ${ }^{23}$ The current approaches to quotation do not acknowledge a predicative function of quotation, whereas the present view accommodates the predicative function of quotation in $(48 \mathrm{a}, \mathrm{b})$ straightforwardly. In (48a), the property expressed by rouge, a property of phatic products, is predicated of 'the translation', the product of the act of translating, and in ( $48 \mathrm{~b}$ ) the property expressed by 'rett', a property of phonetic products, is predicated of the 'pronunciation', the product of the act of pronouncing.

Note that as-phrases can also act as adnominal modifiers of the corresponding product nominalizations:

(49) a. the translation of 'red' as 'rouge'

b. the pronunciation of 'red' as 'rett'

23 By contrast, the direct object position of translate and pronounce is not predicational, but referential, allowing substitution by an explicit expression-referring term and allowing for the 'ordinary' (nonnominalizing) pronoun $i$ :

(i) a. She pronounced / translated the word 'red' as 'rouge'.

b. She had never pronounced / translated it before. 
Pure quotations of course have also syntactic functions other than that of a predicate. ${ }^{24}$

These include other non-referential roles, for example, in close appositions. Close apposition also illustrates well the various ways in which pure quotations can act:

(50) a. the morpheme 'un'

b. the sentence 'it is raining'

c. the concept 'horse'

d. the phoneme 'a'

e. the sound 'shhh'

The non-referential status of the quotation is indicated by the impossibility of replacing the quotation by an explicit referential term ( ${ }^{*}$ the word the word 'maison', * the concept what 'horse' expresses). In close appositions, the pure quotation is not referential on its own, rather the sortal head noun of the close apposition structure has a reifying function, or so I have argued (Moltmann 2013, chapter 6). That is, the sortal head noun involves as part of its semantics a mapping of the semantic contribution of the pure quotation onto a corresponding object, that is, it involves reifying the literal interpretation of the pure quotation with its lower-level linguistic structure, for example, in (5ob) a property of tokens and in (5oc) a conceptual meaning.

Some occurrences of pure quotations may be referential in the sense of involving an implicit close-apposition structure containing an unpronounced sortal noun. This is arguably the case for pure quotations in subject position, as below, where a pure quotation is replaceable by an overt close apposition of a suitable sort:

(5I) a. 'Mary' is disyllabic.

b. The name 'Mary' is disyllabic.

${ }^{24}$ Pure quotations may occur in other predicative contexts, in particular as predicates in small clause complements of verbs of calling:

(i) a. John called Mary 'Marie'.

b. * John called Mary the name 'Marie'.

As Matushansky (2008) argues, 'Marie' in (ia) syntactically has predicative status, in some languages even showing predicative marking. On the present view, pure quotations can play a predicative semantic role, since they express properties of phatic products. However, it is less straightforward to consider names in contexts of calling pure quotations in a predicational function. In that role, they would not be predicated of phatic products, but rather of individuals being named (though of course, it is easy to formulate a suitable property of individuals on the basis of a property of phatic products). 
By contrast, pure quotations in object position tend to be non-referential, not permitting replacement by an overt close apposition, even if the position permits NPs syntactically. Besides say, the verb mean is of that sort. Mean permits instead of a pure quotation an overt close apposition in subject position but not in object position, where only a special quantifier is permitted:

(52) a. 'Red' means 'red'.

b. The word 'red' means 'red'.

c. ???? 'Red' means the concept red.

d. 'Red' means something.

Let me summarize the central idea of this treatment of pure and direct quotation. Both pure and direct quotation involve linguistic structures below the level of LF whose interpretation consists in properties of products of phatic or phonetic acts (or perhaps concept conveying acts). While this is just what those structures should stand for at the level of grammar to which they properly belong, when part of LF, those interpretations will serve as semantic contributions of pure and direct quotes to the composition of the overall meaning of the sentence.

\subsection{Mixed Quotation}

The syntactic and semantic account of pure and direct quotation that the previous section has outlined naturally extends to mixed quotation. In addition to its normal semantic value, a mixed quotation conveys a property characterizing the product of a phatic act. ${ }^{25}$ In a sentence embedded under a verb of saying, this act may be the act described by the embedding verb, as in $(4 \mathrm{Ib})$, repeated below:

(53) a. John said that he 'resides' in Paris.

But the act may also be a contextually given phatic act, as below:

(53) b. John 'resides' in this neighborhood.

In $(53 \mathrm{a}, \mathrm{b})$ the quotation may characterize part of John's utterance, specifying his choice of words in a statement of where he lives.

Like a direct quotation, a sentence containing a mixed quotation has two meanings: its ordinary meaning, a property of attitudinal objects specifying their satisfaction conditions, and a property of products of utterance acts (phonetic or phatic acts). The difference is that with direct quotation, the utterance property is expressed by the entire embedded sentence,

${ }^{25}$ For the idea of a 'dual semantics' of direct and mixed quotation, see also Potts (2007). 
whereas in the case of mixed quotation, it is expressed by a subsentential part. Moreover, with mixed quotation, the utterance property may serve to characterize a contextually given utterance part, rather than the product of the act described by the embedding verb of saying.

The syntactic structure involved in mixed quotation, that is, the basis on which part of a sentence can express a property of part of an utterance, will be similar to that of direct quotation: the quoted expression will have an additional, lower-level linguistic structure at a different plane (or several such structures, a phonological and a morphological structure, say). Again, this structure may be partial or underspecified, but in any case, it will be interpreted 'literally' as a property of products of phonetic or phatic acts.

Sentences with mixed quotations will have the same sort of compositional semantics as direct quotations. This semantics consists in interpreting an LF -structure containing an additional partial lower-level linguistic structure, as a property partially specifying the form of an utterance (a phonetic or phatic product). But in mixed quotation, this property may be predicated of a contextually given utterance, and thus mixed quotation involves a pragmatic element not present in direct quotation.

\section{Conclusion and Outlook}

Austin's notion of a locutionary act and in particular that of a rhetic act has long been considered controversial and unmotivated. This chapter has proposed a way of understanding the notion of a rhetic act within an actrelated semantics and has argued that it plays a central role in the semantics of verbs of saying and of quotation and moreover that it is overtly reflected in natural language, for example, in English words-NPs.

In addition, by making use of Austin's distinction among levels of linguistic acts this chapter has outlined a novel, unified, and compositional semantics of quotation in its various forms. This semantics went along with the syntactic view that quotational structures involve the presence of a lower-level linguistic structure within the syntactic structure that is input to interpretation. The chapter could only give a general outline of this view, though, and the proposals regarding the syntax and compositional semantics of quotation must await full theoretic and formal development. ${ }^{26}$

26 This chapter has greatly benefited from the audiences at the following workshops: "Quotation: Perspectives from Philosophy and Linguistics", Bochum, September 20I2; "NYU Philosophy of Language Workshop", New York University, May 20I2; "Workshop on Quotation”, New York University, April 20I4; "Sentences and Clausal Complements", IHPST, Paris, September 20I5. The chapter has moreover benefited from conversations with Alec Marantz, Jane Grimshaw, Richard Kayne, and Juergen Moltmann, and comments by Savas L. Tsohatzidis. 